\title{
HIV Prevention Concepts-Counter Movements Challenging Societies
}

\author{
Reinhard H. Dennin 1, Arndt Sinn² \\ ${ }^{1}$ Department of Infectious Diseases and Microbiology, University of Luebeck, UKSH, Campus Luebeck, Luebeck, Germany \\ ${ }^{2}$ Centre for European and International Criminal Law Studies (ZEIS), University of Osnabrueck, Osnabrueck, Germany \\ Email: rh.dennin@t-online.de
}

How to cite this paper: Dennin, R.H. and Sinn, A. (2020) HIV Prevention Concepts-Counter Movements Challenging Societies. World Journal of AIDS, 10, 46-68. https://doi.org/10.4236/wja.2020.101005

Received: January 14, 2020

Accepted: March 21, 2020

Published: March 24, 2020

Copyright (c) 2020 by author(s) and Scientific Research Publishing Inc. This work is licensed under the Creative Commons Attribution International License (CC BY 4.0).

http://creativecommons.org/licenses/by/4.0/

\section{(c) (i) Open Access}

\begin{abstract}
This article focuses on emerging trends conflicting current HIV prevention concepts. We address developments in Europe where similar HIV prevention strategies are applied. With epidemiological, time-staggered records from a European institution, we show how ineffective HIV prevention measures have turned out. The decision-makers responsible for these prevention concepts have ignored a multitude of individual motivations from people responsible for the spread of HIV. Both the legal classification of the messages of the prevention campaigns and the obligations of those affected by HIV concerning their social responsibility are analyzed. There are published requirements for updated, multisectoral prevention campaigns. They focus on the intensification of HIV testing concepts to reduce the proportion of late presenters and to link key populations of various kinds to medical and social care services. Four categories present relevant issues with the potential to combine them into suitable arrangements for new prevention concepts.
\end{abstract}

\section{Keywords}

HIV Prevention, Opposing Behavior, Social Responsibility, Social Burden

\section{Introduction}

The epidemiological reports of the European Center for Disease Prevention and Control (ECDC) on the spread of the Human Immunodeficiency Virus (HIV) in European countries in recent years reveal diverging trends. The ongoing spread of person-to-person bound HIV infection has occurred despite national prevention campaigns, which are primarily based on the principles of the New Public Health (NPH) strategy, specifically, a social learning strategy basing on a "doing by learning" concept, also named "inclusion and cooperation", such as messages 
on safe sex and safe drug use with variations depending on the countries. The NPH concept does not follow any restrictive conditions. This strategy may have had some short success in curtailing the spread of HIV at the beginning of the HIV epidemic but no longstanding effects to restrain the spread of HIV. As no adequate studies were conducted back then, there are no science-based data to assess on a large scale any sustaining impact in mitigating HIV epidemics. This strategy resulted in "HIV exceptionalism" with the additional consequence that affected individuals became stigmatized. However, from a scientific point of view, first and foremost, the primary causes of the ongoing spread of HIV have to be addressed; appropriate countermeasures have to be tackled to counteract the sustainable epidemiological developments in the social context.

The primary causes of the ongoing spread of HIV are attributable to too many people who belong to different groups and are not cooperative with the NPH concepts and messages. The campaigns based on these concepts indirectly promoted such behavior as due to excluding measures such as routine testing, reporting HIV-positive patients to official health authorities, and contact and traceability to find index patients. Therefore, help could not be provided to link these people in time with medical and social care services and thereby lower the high percentages of people with a late diagnosis, late presenters; in the European Union (EU) and European Economic Area (EEA) (EU/EEA), the percentage of people presenting at a later stage of HIV infection with insidious depletion of $\mathrm{CD}_{4}$ counts $<350$ cells $/ \mathrm{mm}^{3}$ range up to $>60 \%$, depending mainly on age, gender, and mode of transmission [1]. Reports from the U.S. reveal about 15 percent of approximately 1.1 million people living with HIV are not aware of their HIV infection [2]. Owing to the HIV infection of the CNS, the consequences of causing neurocognitive impairment (even after receiving the antiretroviral medication) [3] and its potential with regard to lacking control of their behavior have been ignored in the context of effective prevention. Prescient warnings to restructure the prevention concepts [4] [5] to end HIV exceptionalism failed [6]. The doubts of UNAIDS on the end of AIDS by 2030 because of gaps in financial support [7] should alert policymakers.

\section{Methodological Approaches}

We used various online services for infectious diseases, public health, social and legal issues, and journals that focus on the topics of HIV/AIDS and other sexually transmitted infections (STIs).

\section{Results}

\subsection{Epidemiology}

First, we show the development of the HIV epidemic for given populations in Europe since 2009.

Figure 1 reveals the development of new HIV diagnoses for populations both 
New HIV diagnoses, by year of diagnosis, transmission $\frac{1}{\mathrm{ec}} \delta \mathrm{C}$ Organization and migration status, EU/EEA, 2009-2018

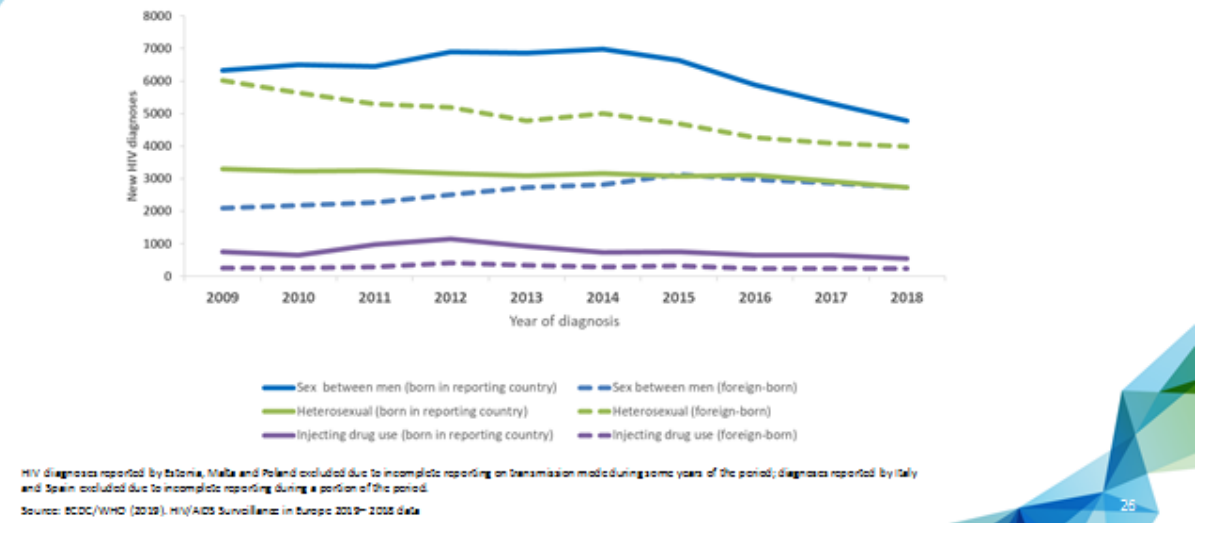

Figure 1. HIV/AIDS surveillance 2019, 2018 data [8].

at-risk [9], heterosexuals and people with a migrant background in the EU/EEA/WHO per year until 2014. After that, partial reducing trends have been observed.

\subsection{People Mainly Affected by HIV Infection}

The World Health Organization (WHO) defined "most-at-risk populations (...) as men who have sex with men, transgender people, people who inject drugs, sex workers and prisoners." [9] This definition should be differentiated to avoid any misunderstanding: these "most-at-risk populations" are not homogenous in their behavior; too few people in these groups have behaved correctly in the context of HIV prevention campaigns, but others belonging to people with multiple risks and overlapping vulnerabilities [9] which have spread and continue spreading HIV, despite combined prevention campaigns. Furthermore, to take account of the changing composition of people listed in the HIV epidemiological data, the WHO definition of those "at-risk" should be extended to certain heterosexual at-risk subpopulations.

We have selected references that concern both the lingering and possibly the recurrence of HIV-1 epidemics. The references point to the urgent adaptation of prevention campaigns, which are tailored to people with still high sexual risk behavior [10]-[15]. It should be noted that misclassifications may have occurred concerning "HIV-1 infections between men" [16] [17]. Furthermore, the impact of sexual networks between transgender women and cisgender men needs further studies [18].

For 2018, regarding the ongoing spread of HIV, background issues were reported for the most affected population in Europe. "Although HIV infection is preventable, significant HIV transmission continues across the WHO European ${ }^{1}$ At-risk practices are those if preventive measures are not taken and certain types of injuries are caused, thereby promoting the transmission of infectious agents such as HIV or HCV. 
Region (...). Sex between men remains the predominant mode of HIV transmission reported in the EU/EEA, (...). Heterosexual contact was the second most common reported mode of HIV transmission in the EU/EEA in 2018, (...).” The transmission of HIV favors males, with an overall male-to-female ratio of 3.1:1.

[8] The same trends have been reported for the previous years. [19] For the "most-at-risk populations" this holds for other countries and even at the global level [20] [21] [22].

The facts that " $\ldots$ almost every second HIV diagnosis happened at a late stage in 2017" [23] and "... 53\% for late HIV diagnosis in 2018 ..." [8] reveal the pitfalls of the voluntary testing concept as part of the HIV Prevention Strategy in these countries. Although the NPH strategy is a necessary component it can only be a supplementary part of HIV prevention campaigns. In contrast to community acquired infections, the strictly person-to-person bound HIV infection requires additional elements, such as early testing and "notification systems." This approach would enable public health services to trace back the chains of infection for counseling the very early sources spreading HIV, but it requires the cooperation of those concerned.

\subsection{Quite Different Aspects: A Look at Certain Anatomical Peculiarities}

Certain anatomical peculiarities regarding the anal canal are worth being considered in the context of both HIV, HCV transmission and prevention issues. The at-risk sexual behavior of heterosexual people, and in particular of MSM, is based on both unprotected vaginal (UVI) and anal intercourse (UAI), apart from the disposition of MSM for promiscuity. Related analyses support the experience that, under such conditions, the likelihood of HIV transmission during anal intercourse seems to be higher than during vaginal intercourse [24]. "There was no significant difference between per-act risks of UAI for heterosexuals and MSM" [25]. Certain anatomical features could contribute to explain these situations. The lower and the upper part of the anal canal are connected by the transitional zone (linea dentata). It is covered by a mucosa much flatter and thinner than in the adjacent sections, where there is a multilayered squamous or glandular cryptal epithelium, respectively. Mucosal defects, which are due to microtrauma during intercourse and a prerequisite for transmission of sexually transmitted infections (STIs), such as HIV, are much more common in this anal region than in other parts lined with a thicker and more protective mucosa. At the cervix, the mucous membrane of the transitional zone is similar but shorter. Since the connection between the endo- and ectocervix is normally hidden in the cervical canal, the transmission risk in the vagina and cervix may be lower than in the anal canal.

If controlled demonstrations prove that this anal anatomical feature is responsible for increased HIV transmission during UAI, the use of condoms should be mandatory if UAI is intended, not only because of HIV but also given other 
sexually transmitted infections as well. ${ }^{2}$ The hint to the type of transmission of HCV such as "Sexual transmission is unusual with the exception of MSM," could also support this preventive measure [26].

\section{Why Could the Spread of HIV Reach the Current Dimension?}

\subsection{Growing Concern on This Scenario Comprises Three Main Categories with Overlapping Issues}

1) The HIV prevention campaigns in most countries follow liberal guidelines that are based on the principles of the NPH and similar concepts. A recap: a) This "doing by learning" concept is based on correct messages to avoid the risky sexual behavior of a person and IDU; these legally non-binding messages address people to prevent themselves or partners from becoming infected with HIV. The decision-makers responsible for this concept have misjudged and ignored the variety of overlapping vulnerabilities. Conditions such as social disparities, mental disorders, and learning difficulties of the people at risk pose intricate circumstances of behaviors in the target groups. The decision-makers have naively disregarded that messages addressing the cognitive level of the most affected people never can thoroughly and permanently modify the ingrained emotionally guided sexual behavior [27]. This concept failed to persuade a high enough proportion of vulnerable people to follow behavior based on the correct prevention messages and last not least ethical principles; instead, they continued with risky behaviors that can harm themselves and others with HIV infection and other sexually and blood borne transmitted diseases. Initially, the focus of the prevention campaigns was on HIV infection; other STIs followed later.

b) The campaigns were aimed at the "general public", but there was a lack of tailored messages for vulnerable people who follow "at-risk" lifestyles in the aforementioned context [28]. Selected reviews analyzing risky sexual behavior in MSM reveal its scenarios in the real world [29] [30] [31]. The granted unrestricted autonomy of self-determined sexual behavior lacks any consideration of the various real patterns of behavior of the people concerned here. ${ }^{3}$ If any, only short- term effects could be expected to modify their behavior [32]. The underlying analysis of the epidemiological data shows that the feared collapse into the so-called general population in developed countries has not taken place, although it is an ongoing process, considering the increasing HIV prevalence in heterosexual populations. For future adjustments of prevention campaigns, it must be considered that "bridging people" from the at-risk MSM population may return to "heterosexual" lifestyles and vice versa, with the potential to spread HIV into the "general population".

c) In addition to it, new trends show unambiguous claims to reject HIV pre-

${ }^{2}$ We thank PD Dr. med. R. Schmauz, Pathologist, for his contribution regarding anatomical features of the anal canal; 26871 Papenburg, Germany, 2019.

${ }^{3}$ Several countries of the EU have invented surveillance care systems that allow physicians to obtain the comprehensive health status of their patients. 
vention measures in favor of “... gay men's right to pleasure ...” [33]. Such claims look like advertising to insist on at-risk behavior and document their predominant non-responsibility for partners and society.

State of the art is: the actual prevalence of HIV in the EU/EEA since the beginning and the increasing trends disapprove official assertions of the chosen $\mathrm{NPH}$ concept being thoroughly successful; it has only worked in part and been effective only with a too low number of insightful people who are ready to learn and change their behavior toward risk reduction. New prevention campaigns recommended by the WHO [34] might also be powerless unless those campaigns get combined with appropriate case-by-case measures listed in chapter V. The same holds for more stringent management of established prevention concepts coordinated in an "HIV prevention cascade" [35].

2) Additional support for ending the trajectory of HIV pandemic was hoped for by the invention of biomedical approaches. With the introduction of combined Antiretroviral Treatment (cART) in the late 1990s, it was expected that, by reducing the HIV load (viral load, VL) in the blood of HIV-infected and treated individuals, their infectiousness could be reduced and thus decrease the spread of HIV. Regarding the individual's HIV infectiousness, strict adherence with cART is necessary to lower the HIV VL below the level in the blood that indicates "not infectious" according to the "undetectable equals untransmittable (U = U)" message [36]. However, this "treatment as prevention" (TASP) [37] [38] concept requires consistent, lifelong adherence to cART to improve the individual's health, but depending on comorbidities of different causes. Yet, this equation is too simple with regard to the individual versus the population level [39]. It is also important to avoid the potential of the spread of cART-resistant HIV [40]. In this context, the initiative of the ECDC to establish an HIV drug resistant surveillance system is a necessary measure [41]. The invention of pre-exposure prophylaxis (PrEP), containing a combination of certain anti-HIV drugs, followed in about 2015. The accumulated epidemiological data did not show the expected rapidly decreasing spread of new HIV infections. It was not until 2014/2015 that a slight slowdown became apparent. There are reports revealing some success reducing new HIV infections due to cART and PrEP [42] However, there are indications for diversity in this success, which require stringent evaluations of "a more complex reality" and consequences from there [43] [44].

3) Contradictory at first glance: Based on a multitude of studies, the overarching reason for the yet ongoing spread of HIV seems to be connected with the availability of medications against HIV infection with the side effect of resurgences of other STIs [45]. The resulting ongoing, sometimes resurgent HIV-1 epidemics in at-risk populations is attributable to the less threatening and therefore diminishing fear of death attributable to the availability of cART, PrEP and PEP, leading to a "decline in prevention behavior"; 4 [46] [47] i.e., recovery to risky sexual behavior [48], essentially unprotected anal intercourse [49] [50] [51] [52] [53]. There are reservations linking the use of PrEP with "access for every${ }^{4}$ PEP, Post-Exposure Prophylaxis. 
one", "adherence" and the "public health benefit" [54]. However, a representative study in Europe about the risk behavior among MSM reflects the dire consequences of cART on preventive measures [55].

PrEP has been and is being taken by too many members of the target groups as a form of insurance against HIV infection. As a result, too many of these people continue to engage in risky behavior rather than adhering to HIV prevention messages, which can also help to prevent other STIs with shared routes of transmission.

As a consequence of the availability of medications against HIV, the resurgence in the epidemics of HIV and other STIs was already foreseen in 2002 [56]. The epidemiologic data for syphilis in EU/EEA Member States for the period 2007-2017 confirmed the foreseen trends [57] [58]. In Germany, the increase of prevalence of HIV and hepatitis B and C in IDU [59] was observed, while in the US, the high prevalence of HCV in HIV-infected MSM [60] and syphilis in MSM continued to account for the majority of primary and secondary syphilis cases in 2017 [61]. In Germany, syphilis infections in MSM continued in 2017 [62]. The increasing prevalence of syphilis and HCV in these vulnerable groups in various countries is indication that they have maintained their risky behaviors, despite the correct messages from prevention campaigns (especially concerning safe sex and safe use). This is because safe sex and safe use can also protect against other sexually and blood-borne transmitted infections. Even with the availability of vaccination programs for hepatitis $A$ and $B$, their spread is ongoing [63]. The relevance of such scenarios to social concerns was never considered.

\subsection{Modern Trends}

\section{1) Changed perception of social understanding and consequences}

With the development of the "Open Society" [64], a certain kind of individualism became a prevailing trend for many people of modern society. The societal currents coined by libertarian ideologies (i.e., disregarding science-based facts about human behavior and of legal norms in states with constitutions based on rules of law) have led to radical individual behavior for too many people mentioned here. Such individualized behavior can only be tolerated if it does not result in disadvantages for others and causes no detriment to society. However, this kind of individualism has led to too many at-risk people avoiding social responsibility by making void their duties to society. Besides, under the protection of HIV exceptionalism, [6] [65] sub-populations of high-risk MSM abused these trends by assuming unwritten rights to engage in risky sexual behaviors: unconditional selfishness goes before the protection of the common good. When it comes to the use of recreational drugs, also referred to as "sexualized drug use," extreme situations may develop in such venues, in particular "chemsex" or swinger settings [66] [67]. That is, using increasing rates of "recreational" party drugs up to opioids when having sex [68] [69] [70] [71]. Such cluster meetings of the vulnerable groups mentioned here have consequences: As the relative compaction of HIV-infected people both with and without cART is higher during 
these meetings than in situations of casual dates, these cluster arrangements provide a favorable potential for more effective spread of HIV and other STIs. Furthermore, these situations include the potential for HIV to spread its changing virulence; [73] and double or even multiple superinfections with HIV among participants infected with HIV of different clades may happen, thereby providing conditions for recombination at their genomic DNA level resulting in circulating recombinant forms (CRFs) [73]. The analysis of at-risk people susceptible to chemsex settings highlights a variety of reasons why current prevention concepts are unrealistic tools [74] [75] [76]. Apart from their long-term adverse health effects on misuse of recreational drugs, users may lose cognitive control when taking these drugs in these types of settings, even being unable to manage their behavior [77]. Such kinds of patterns of behavior are an integral part of the "Risk Society" [78].

2) Changed perception of legal and constitutional aspects opposing certain fundamental principles of social responsibility

In this context, the comment of the UNAIDS Reference Group on HIV and Human Rights (HRHIV) seems a disconcerting one when only referring to the rights of people living with HIV, but does not mention their obligations, such as "duties to the community," under Article 29 of HR [79]. The public's reminder to protect human rights for people living with HIV is a welcome message. However, this statement from HRHIV reflects a blanket and undifferentiated assessment of the behavior of HIV-infected at-risk individuals. Because the reality of the behavior of those who are to be addressed here is as follows: Many of whom continue risky behavior, thereby promoting HIV spreading but complain suffering from discrimination and stigma. Therefore, not demanding their obligations, such as not spreading their HIV infection and not harming the community, displays a biased stance in favor of those who behave irresponsibly; too many of whom are not interested in ethical and social norms, they counteract the "duties to communities." Instead of ignoring the message of the ECDC/WHO that “... HIV infection is preventable ..." [8], it is precisely this Reference Group of UNAIDS that should spread reminders to the at-risk people to adapt their behavior in the sense of subordination to the duties for the communities because of its consequences, such as the grave financial burden on societies [80].

German constitutional law contains numerous rights of citizens, which are described as rights of the citizen against the state in the form of fundamental rights. However, the constitutional law also imposes certain protection obligations on the state. One such obligation is the protection of human life, which it must fulfill as a last resort of state intervention and also by means of criminal law." This duty to protect has its reason in Article 1.1 of the "German Grundgesetz" $\left(\mathrm{GG}^{5}\right)$, which expressly obliges the state to respect and protect human dignity; its object and, from its point of view, measure are defined in more detail by Article 2.2 of the GG. ${ }^{6}$

${ }^{5}$ The German Basic Law (GG) represents the German constitution.

${ }^{6}$ BVerfGE 88, 203 (251); Bundesverfassungsgericht; the German Federal Constitutional Court. 
For the intentional or negligent killing or bodily injury caused by transmission of HIV or the HIV-infected person intending to kill or injure with knowledge of their HIV-positive status, general criminal offenses, therefore, also apply in Germany. This follows an abstract concept for the protection of life and physical integrity without punishing a special offense in which the manner of injury to another person is specifically described by the transmission of HIV.

Criminality begins where another person intentionally or negligently kills, injures or intentionally attempts to kill another person by transmitting a HIV infection (cf. BGHSt 36, 1) ${ }^{7}$. However, this abstract protection concept poses certain challenges for criminal prosecution, because on the one hand, it is scientifically not easy to prove the connection (causality) between the act of injury (HIV transmission) and the illness of the infected person due to the high variability of the HIV genome. If this proof is not successful, at least an attempted killing or injury can still be punished if the perpetrator acted intentionally. In this context, it is important that intentional behaviour must not only contain knowledge of one's own infection and the possibility of transmission but also the will to cause the infection of another person. In court practice, this will is generally denied with regard to killing and only affirmed with regard to bodily injury (e.g., BGHSt 36,1$)$. Also, the intake of antiviral drugs has an influence on the intention of the infected person, because by lowering the viral load, the knowledge of the contagiousness and the will to infect another person can no longer be established.

Even a link to the particularly dangerous nature of an HIV-infected person during unprotected sexual intercourse can no longer be established with antiviral drugs. What remains is the autonomy of a person who has unprotected sexual intercourse with an infected person who is considered an injured good. However, this autonomy is not protected by German criminal law. Consensual sexual intercourse in ignorance of the partner's infection is therefore not punishable by law, as far as an intentional or negligent transmission cannot be proven and also the intention cannot be established. This complicated interaction of criminal law attribution mechanisms shows that, in Germany, there is no discrimination against HIV-infected persons through criminal law, which is why the call for decriminalization is misplaced. It also becomes clear, however, that this concept places the protection of life and physical integrity at the center of criminal prosecution and not the autonomy of a person who is consciously unaware of the illness of the person with whom he or she interacts. The preventive role of criminal law in such an area must not be overestimated, because criminal law always deals with the past and with the crime committed. Whether persons are deterred by criminal offenses is very questionable, especially in the emotional area of sexuality. Criminal law is not a cure or a medicine.

Certainly, antiviral drugs are a means of containing the transmission of HIV. However, it should not be overlooked that this is not the only means, because these drugs reduce the risk of new infections, but do not reduce it to zero as ${ }^{7}$ BGHSt, Bundesgerichtshof, Strafsachen; the German Federal Supreme Court. 
could be shown in controlled studies. Another preventive element must be added: the protection of autonomy by informing the sexual partner. For it is only through knowledge of the potential danger of unprotected sexual intercourse that the risk can be further reduced, either by avoiding contact or by taking protective measures. Only through this prevention concept would the four basic ethical principles (non-damage, duty of care, self-determination, and justice) in dealing with the preparation of HIV be fulfilled. ${ }^{8}$

Outside of criminal law, too, the state has to fulfill its obligation to protect these four basic principles in its prevention strategies by including and clearly addressing them therein. Antiviral drugs do not compensate for the loss of autonomy. Consensual sexual intercourse with knowledge of the partner's HIV infection remains autonomous. If an HIV infection is acquired by ignoring preventive measures, the consequences of this behavior will burden the community of solidarity. In Germany, there are regulations that say the costs for diseases brought on by one's fault can be imposed on those affected. ${ }^{9}$ However, there should be problems with the burden of proof.

\section{Challenges for Societies in the Future}

Besides the high prevalence of HIV and regional differences in HIV incidences, there are multitudinous sequelae of various categories piling up

1) Those in charge of HIV prevention concepts have spurned all realities by not noticing the ongoing non-cooperation of too many people in the various sexual oriented at-risk communities with regard to prevention campaigns. In effect, these people were allowed to continue engaging in risky sexual behavior. The same holds for people who use psychoactive substances of different kind by injection (people who inject drugs, PWID/IDU), toking, respectively. Focusing only on the HIV infection was disobeying the additional several decades long care services necessary for various co-infections and HIV-related co-morbidities [81] [82] [83] [84] [85]. In particular, this concerns the scourges of neurologic and other disorders of the aging HIV-infected population [86] [87] [88].

2) In addition to the ongoing spread of HIV among high-risk groups like concentrated epidemics, the spread of STIs has developed into generalized epidemics depending on the country. As the global prevalence of $\mathrm{HCV}$-infected people is about five to six times higher as compared to HIV, we briefly focus on both the mono hepatitis C infection and HCV co-infections in HIV-infected patients. The increasing incidence of HCV, [89] [90] [91] syphilis, other STIs and HIV-related comorbidities of different kind [92] in the at-risk groups in particular is irrefutable proof of their non-cooperative behavior with prevention campaigns. Their behavior reflects their rejection of duties to societies and may contribute to social tensions.

${ }^{8}$ (cf. Tom L. Beauchamp/James F. Childress, Principles of Biomedical Ethics, 8th edition 2019). ${ }^{9}$ SGB Sozialgesetzbuch (SGB V) - Fünftes Buch - Gesetzliche Krankenversicherung (Statutory health insurance) - Stand: Zuletzt geändert durch Art. 2 G v. 11.12.2018 I 2387; $₫ 52$ SGB V Leistungsbeschränkung bei Selbstverschulden (in German only). 
The efforts for HCV prevention within certain regional MSM communities pose startling scenarios [93]. The increase in HCV infections based on cases diagnosed [94] [95] [96] as STIs is also seen as a challenge for society. Apart from the treatment of HCV in HIV/HCV co-infected patients, comments already hint at the transfer of the Treatment as Prevention (TASP) concept for mono HCV-infected patients [97] [98]. For PWID, existing needle and syringe programs have proved cost-effective, [99] but it needs sufficient offers of HCV harm reduction centers [100] [101].

3) As for the costs

Finally, because of insufficient prevention campaigns and the various groups of unreasonable people who continue to counter the right prevention messages, policymakers need to be reminded of the costs to society [102] [103] [104] [105].

Studies on interactions of HIV infection with co-infections, such as HCV [106] [107] and HCV reinfections, pose challenges for customized prevention concepts [108] [109] [110].

\section{Which Kind of Issues Have Emerged That Has to Be Managed to Curb, to Contain the Ongoing Spread of HIV the EU/EEA?}

Certain facts need to be mentioned: there are too many people from different at-risk groups, some of whom may not understand and do not comply with the prevention campaigns, others know about the risks, but block out the perception of risks. They negate possible detrimental health effects and intentionally continue risk behavior. Moreover, these people are abusing biomedical approaches to engage in unprotected sexual behavior and drug use, thereby preserving the potential for the spread of HIV and other sexually transmitted and blood-borne diseases. They refuse to help to stop HIV epidemics. These are compelling reasons to modify the existing framework conditions. The HIV transmission is strictly person-to-person bound and, apart from semen and rectal secretion, mainly a blood-borne infection, that is, with shared routes such as HBV and HCV. Therefore, established and proven rules according to the Old Public Health $(\mathrm{OPH})$ concepts have to be applied, such as back-tracing HIV infection chains to reduce the prevalence of late presenters with their potential to uphold at least regional HIV epidemics. In particular, this holds for people belonging to the at-risk population; too many of them reject testing for HIV but continue their risk behavior, although possibly living unaware with HIV infection. Insofar, it is noteworthy that in recent years, many comments have called for these $\mathrm{OPH}$ rules to be implemented in order to curb the ongoing spread of HIV and other STIs, which means a return to established rules.

Most of the issues listed below have been selected from the references listed under References, but are not cited here again.

Preliminary remarks: We would like to note that only the combination of various measures related to specific situations may be helpful to reach the curb- 
ing of the HIV epidemic [111] [112] [113]. There is also a complex need to adapt and implement current prevention campaigns to address the overlapping vulnerabilities of various at-risk key populations in modern societies [114] [115]. Without a preventive vaccination, the vision "End of AIDS" remains questionable.

1) HIV testing: People living unaware with their HIV infection present an unmanageable potential to keep upright, at least regional HIV epidemics; a multitude of benefits may result when reaching these people for testing for HIV and other STIs; this approach can help to reduce those who currently present with a late HIV diagnosis, late presenters [116]. The goal is to help them get treatment and link them to the respective healthcare services in the context of the TASP concept and medical service for acute and persistent health problems [117].

a) Increasing testing:

Offers for testing in various facilities, arrangements:

i) Designing offers for testing have to consider the grievous and various reservations of vulnerable people, as well as their educational, social and cultural backgrounds;

ii) When visiting a physician: offering a test if indications are given for risk behavior, for a STI upon a doctor's impression;

iii) Outreach testing depending on the situation (e.g., peculiar situations need analyses for migrants crossing borders) [118].

b) Above all, the outreach testing for the late presenters gets advocated [119].

c) The consequent "...support for HIV testing and engagement in clinical care ...” reveal positive ramifications on reducing at-risk behavior [120] [121].

With enforced linking, infected individuals receive ongoing HIV care, ensuring that they remain engaged in care testing for HIV.

d) However, if free confidential testing fails to get enough individuals tested, then mandatory testing should be considered.

2) Behavior: Appropriate measures to help vulnerable people adopt behavior compliant with the HIV prevention messages:

a) A superordinate strategy: motivational interviews - determination of positive aspects for the future of the individual;

b) Individual counseling for the health consequences of HIV infection, despite cART;

c) Counselling structure:

i) Individual: emphasis on socioeconomic factors;

ii) In groups: supported and guided by peers;

d) Counselling issues:

i) Informing about fallouts of:

- serosorting, partner switching extended to LGBTQ ${ }^{10}$;

- partner notification: non-consensual sex, non-disclosure of HIV status;

ii) Medical services: treatment of mental/psychological illness, mostly to reduce fear of HIV testing;

${ }^{12} \mathrm{LGBT}$, lesbian, gay, bisexual, and transgender. 
iii) Sexual promiscuity itself;

iv) Interventions advising to reduce/quit risky sexual behavior;

v) Taking care of new generations following those of the 1980s

vi) Tailored approaches regarding change in generations: different perspectives of "modern" lifestyles

vii) Survival sex, exchange for recreational drugs;

viii) Tailored information on higher risk of acquiring HIV and other STIs in organized settings and engaging in overlapping sexual networks.

3) HIV care services:

a) Such services have to consider that many of the people in question here are homeless, helpless, uninformed, and have no chance of getting information on what to do;

b) To intervene in the increasing rates of patients lost to follow-up;

c) Various stages of care: reducing gaps in healthcare services [122];

d) "Combination prevention", which incorporates biomedical, behavioral, social and structural interventions, should be explored further [123];

e) Appropriate help for people who need cART, PrEP and PEP to follow the respective drug revenues [124]. Respective measures should be checked given increasing STI prevalence in the at-risk populations [45] [125].

4) Misuse of "recreational" drugs [126] and information for:

a) IDU on the serious problems to health caused by long-term use;

b) IDU on drug consumption facilities, safe consumption spaces, and exchange offers for needles and syringes;

c) People participating in group sex events: Intensified education, the aftereffects when using recreational drugs both to relieve and endure chronic pain.

The list above discloses the necessary measures that should have been taken into account by decision makers for HIV prevention campaigns since the outbreak of HIV epidemics.

The message of the WHO and "why the HIV epidemic is not over" should make policymakers aware that realistic alterations in prevention strategies in the context of treatment approaches are urgently necessary [34].

\section{Conclusions}

The liberal basis of HIV prevention campaigns, such as the NPH concept, has allowed unrestricted freedom, mainly of sexual self-determination, without paying attention to social responsibility. This review reveals maldevelopments of the HIV epidemics as a result of these campaigns.

The HIV prevention campaigns have failed in their goal to curtail the spread of HIV. Contrary to the right messages, the people affected here have developed rules of conduct that promote negligence with the consequence of harming health of the partners. They do not take into account the individual obligations in the context of the common good and constitutions. Self-realization is acceptable, but any harmful consequences thereof must not be at the expense of socie- 
ty, given the gained scale. Necessary adjustments are required to curb the ongoing spread of HIV and other STIs with increasing prevalence. In addition to supporting society and care facilities, regulations must be developed to encourage at-risk people of different backgrounds to cooperate with the right messages of the prevention campaigns. The supplementary biomedical approaches with antiretroviral drugs are connected with imponderables. "There is a real risk of HIV resurgence due to several factors, including injection drug use and diagnostic complacency among healthcare providers" [127].

\section{Conflicts of Interest}

The authors declare no conflicts of interest regarding the publication of this paper.

\section{References}

[1] European Centre for Disease Prevention and Control (2018) Infographic: HIV Late Diagnosis: 2017 Data.

https://www.ecdc.europa.eu/en/publications-data/infographic-hiv-late-diagnosis-20 17-data

[2] HIV.gov (2019) Too Many People Living with HIV in the U.S. Don't Know It. https://www.hiv.gov/blog/too-many-people-living-hiv-us-don-t-know-it?utm_sour ce=email\&utm_medium=email\&utm_campaign=weekly20190614

[3] Spudich, S., Robertson, K.R., Bosch, R.J., et al. (2019) Persistent HIV-Infected Cells in Cerebrospinal Fluid Are Associated with Poorer Neurocognitive Performance. Journal of Clinical Investigation, 129, 3339-3346. https://doi.org/10.1172/JCI127413

[4] Beck, A., McNally, I. and Petrak, J. (2003) Psychosocial Predictors of HIV/STI Risk Behaviors in a Sample of Homosexual Men. Sexually Transmitted Infections, 79, 142-146. https://doi.org/10.1136/sti.79.2.142

[5] Rotheram-Borus, M.J., Swendeman, D. and Chovnick, G. (2009) The Past, Present, and Future of HIV Prevention: Integrating Behavioral, Biomedical, and Structural Intervention Strategies for the Next Generation of HIV Prevention. Annual Review Clinical Psychology, 5, 143-167.

https://doi.org/10.1146/annurev.clinpsy.032408.153530

[6] Bayer, R. and Fairchild, A.L. (2006) Changing the Paradigm for HIV Testing-The End of Exceptionalism. The New England Journal of Medicine, 355, 647-649. https://doi.org/10.1056/NEJMp068153

[7] UNAIDS (2019) Global AIDS Update 2019-Communities at the Centre. https://www.unaids.org/sites/default/files/media_asset/2019-global-AIDS-update_e $\underline{\text { n.pdf }}$

[8] European Centre for Disease Prevention and Control, WHO Regional Office for Europe (2019) HIV/AIDS Surveillance in Europe 2019-2018 Data. ECDC, Stockholm.

https://www.ecdc.europa.eu/sites/default/files/documents/HIV-annual-surveillance -report-2019.pdf http://ECDC-WHO-HIV-surveillance-report-2018-data.pptx

[9] World Health Organization (WHO) (2011) Global Health Sector Strategy on HIV/AIDS 2011-2015.

http://whqlibdoc.who.int/publications/2011/9789241501651_eng.pdf 
[10] Johnson, W.D., Diaz, R.M., Flanders, W.D., et al. (2008) Behavioral Interventions to Reduce Risk for Sexual Transmission of HIV among Men Who Have Sex with Men. Cochrane Database of Systematic Reviews, 16, CD001230. https://doi.org/10.1002/14651858.CD001230.pub2

[11] Crepaz, N., Marks, G., Liau, A., et al. (2009) Prevalence of Unprotected Anal Intercourse among HIV-Diagnosed MSM in the United States: A Meta-Analysis. AIDS, 23, 1617-1629. https://doi.org/10.1097/QAD.0b013e32832effae

[12] Bengtsson, L. and Thorson, A. (2010) Global HIV Surveillance among MSM: Is Risk Behavior Seriously Underestimated? AIDS, 24, 2301-2303. https://doi.org/10.1097/QAD.0b013e32833d207d

[13] McDaid, L.M. and Hart, G. (2010) Sexual Risk Behaviour for Transmission of HIV in Men Who Have Sex with Men: Recent Findings and Potential Interventions. Current Opinion in HIV and AIDS, 5, 311-315. https://doi.org/10.1097/COH.0b013e32833a0b86

[14] Fenton, K. (2013) The Resurgent Global HIV Epidemic in Men Who Have Sex with Men (MSM). Plenary Lecture, BHIVA Autumn Conference.

https://www.bhiva.org/file/zkSwsEmuaKOje/KevinFenton.pdf

[15] Hess, K.L., Crepaz, N., Rose, C., Purcell, D. and Paz-Bailey, G. (2017) Trends in Sexual Behavior among Men Who Have Sex with Men (MSM) in High-Income Countries, 1990-2013: A Systematic Review. AIDS and Behavior, 21, 2811-2834. https://doi.org/10.1007/s10461-017-1799-1

[16] Hué, S., Brown, A.E., Ragonnet-Cronin, M., Lycett, S.J., Dunn, D.T., Fearnhill, E., Dolling, D.I., Pozniak, A., Pillay, D., Delpech, V.C., Leigh Brown, A.J. and UK Collaboration on HIV Drug Resistance and the Collaborative HIV, Anti-HIV Drug Resistance Network (CHAIN) (2014) Phylogenetic Analyses Reveal HIV-1 Infections between Men Misclassified as Heterosexual Transmissions. AIDS, 28, 1967-1975. https://doi.org/10.1097/QAD.0000000000000383

[17] Schrimshaw, E.W., Downing, M.J. and Cohn, D.J. (2018) Reasons for Non-Disclosure of Sexual Orientation among Behaviorally Bisexual Men: Non-Disclosure as Stigma Management. Archives of Sexual Behavior, 47, 219-233. https://doi.org/10.1007/s10508-016-0762-y

[18] Ragonnet-Cronin, M., Hu, Y.W., Morris, S.R., Sheng, Z., Poortinga, K. and Wertheim, J.O. (2019) HIV Transmission Networks among Transgender Women in Los Angeles County, CA, USA: A Phylogenetic Analysis of Surveillance Data. Lancet $H I V$, 6, e164-e172. https://doi.org/10.1016/S2352-3018(18)30359-X

[19] European Centre for Disease Prevention and Control/WHO Regional Office for Europe (2008) HIV/AIDS Surveillance in Europe 2007. European Centre for Disease Prevention and Control, Stockholm.

https://www.ecdc.europa.eu/sites/default/files/media/en/publications/Publications/ 0812_SUR_HIV_AIDS_surveillance_in_Europe.pdf

[20] HIV.gov, Centers for Disease Control and Prevention, USA (2019) Source: CDC, HIV Incidence: Estimated Annual Infections in the U.S., 2010-2016. U.S. Statistics, Fast Facts. https://www.hiv.gov/hiv-basics/overview/data-and-trends/statistics

[21] Crepaz, N., Hess, K.L., Purcell, W. and Hall, H.I. (2019) Estimating National Rates of HIV Infection among MSM, Persons Who Inject Drugs, and Heterosexuals in the United States. AIDS, 33, 701-708. https://doi.org/10.1097/QAD.0000000000002111

[22] Beyrer, C., Sullivan, P., Sanchez, J., Baral, S.D., Collins, C., Wirtz, A.L., Altman, D., Trapence, G. and Mayer, K. (2013) The Increase in Global HIV Epidemics in MSM. AIDS, 27, 2665-2678. https://doi.org/10.1097/01.aids.0000432449.30239.fe 
[23] European Centre for Disease Prevention and Control, WHO Regional Office for Europe (2018) HIV/AIDS Surveillance in Europe 2018-2017 Data. WHO Regional Office for Europe, Copenhagen.

https://www.ecdc.europa.eu/en/publications-data/presentation-hivaids-surveillance -europe-2018-2017-data

https://www.ecdc.europa.eu/en/publications-data/infographic-hiv-late-diagnosis-20 17-data

[24] Centers for Disease Control and Prevention (CDC); Division of HIV/AIDS Prevention, National Center for HIV/AIDS (2015) Viral Hepatitis, STD, and TB Prevention, Centers for Disease Control and Prevention. HIV Risk Behaviors. https://www.cdc.gov/hiv/risk/estimates/riskbehaviors.html

[25] Baggaley, R.F., White, R.G. and Boily, M.-C. (2010) HIV Transmission Risk through Anal Intercourse: Systematic Review, Meta-Analysis and Implications for HIV Prevention. International Journal of Epidemiology, 39, 1048-1063.

https://doi.org/10.1093/ije/dyq057

[26] Chi, A. (2019) Pharmacy Essentials for HCV Screening and Management. Clinical Care Options.

https://www.clinicaloptions.com/hepatitis/programs/pharmacy-care/hcv-screening/ pharmacy-hcv-slides

[27] Crepaz, N. and Marks, G. (2002) Towards an Understanding of Sexual Risk Behavior in People Living with HIV: A Review of Social, Psychological, and Medical Findings. AIDS, 16, 135-149. https://doi.org/10.1097/00002030-200201250-00002

[28] The Health Hazards of Homosexuality (2020) "Gay" (MSM) Sexual Practices \& Disease. How Today's “Gay” Subculture Is Different excerpt from Chapter 6. http://www.healthhazardsofhomosexuality.info/msm-sex.html

[29] Klein, H. (2009) Sexual Orientation, Drug Use Preference during Sex, and HIV Risk Practices and Preferences among Men Who Specifically Seek Unprotected Sex Partners via the Internet. International Journal of Environmental Research and Public Health, 6, 1620-1635. https://doi.org/10.3390/ijerph6051620

[30] Lewnard, J.A. and Berrang-Ford, L. (2014) Internet-Based Partner Selection and risk for Unprotected Anal Intercourse in Sexual Encounters among Men Who Have Sex with Men: A Meta-Analysis of Observational Studies. Sexually Transmitted Infections, 90, 290-296. https://doi.org/10.1136/sextrans-2013-051332

[31] Basten, M., Heijne, J.C., Geskus, R., Den Daas, C., Kretzschmar, M. and Matser, A. (2018) Sexual Risk Behaviour Trajectories among MSM at Risk for HIV in Amsterdam, the Netherlands. AIDS, 32, 1185-1192. https://doi.org/10.1097/QAD.0000000000001803

[32] Berg, R. (2009) The Effectiveness of Behavioural and Psychosocial HIV/STI Prevention Interventions for MSM in Europe: A Systematic Review. Surveillance, 14, 19430. https://doi.org/10.2807/ese.14.48.19430-en

[33] Garner, A. (2019) We Need to Look beyond HIV. https://www.avert.org/news/alex-garner-\%E2\%80\%98we-need-look-beyond-hiv\%E $2 \% 80 \% 99$

[34] WHO (2020) Why the HIV Epidemic Is Not Over. https://www.who.int/hiv-aids/latest-news-and-events/why-the-hiv-epidemic-is-notover

[35] Krishnaratne, S., Hensen, B., Cordes, J., Enstone, J. and Hargreaves, J.R. (2016) Interventions to Strengthen the HIV Prevention Cascade: A Systematic Review of Reviews. The Lancet HIV, 3, e307-317. 
https://doi.org/10.1016/S2352-3018(16)30038-8

[36] Eisinger, R.W., Dieffenbach, C.W. and Fauci, A.S. (2019) HIV Viral Load and Transmissibility of HIV Infection: Undetectable Equals Untransmittable. JAMA, 321, 451-452. https://doi.org/10.1001/jama.2018.21167

[37] Vernazza, P., Hirschel, B., Bernasconi, E. and Flepp, M. (2008) Les personnes séropositives ne souffrant d'aucune autre MST et suivant un traitement antirétroviral efficace ne transmettent pas le VIH par voie sexuelle. Bulletin des médecins suisses, 89, 165-169. (In French) https://doi.org/10.4414/bms.2008.13252

[38] Rodger, A.J., Cambiano, V., Bruun, T., et al. (2019) Risk of HIV Transmission through Condomless Sex in Serodifferent Gay Couples with the HIV-Positive Partner Taking Suppressive Antiretroviral Therapy (PARTNER): Final Results of a Multicentre, Prospective, Observational Study. The Lancet, 393, 2428-2438.

https://doi.org/10.1016/S0140-6736(19)30418-0

[39] Baral, S., Rao, A., Sullivan, P., Phaswana-Mafuya, N., Diouf, D., Millett, G., Musyoki, H., Geng E. and Mishra, S. (2019) The Disconnect between Individual-Level and Population-Level HIV Prevention Benefits of Antiretroviral Treatment. The Lancet $H I V, 6$, e632-e638. https://doi.org/10.1016/S2352-3018(19)30226-7

[40] Abela, I.A., Scherrer, A.U., Böni, J., et al. (2019) Emergence of Drug Resistance in the Swiss HIV Cohort Study under Potent Antiretroviral Therapy Is Observed in Socially Disadvantaged Patients. Clinical Infectious Diseases, 70, 29-303. https://doi.org/10.1093/cid/ciz178

[41] Bosman, A. and Van De Laar, M. (2019) Developing a Reporting System for the Surveillance of HIV Drug Resistance in Europe. ECDC, Stockholm.

[42] Le Guillou, A., Pugliese, P., Raffi, F., et al. (2019) Reaching the Second and Third UNAIDS 90-90-90 Targets Is Accompanied by a Dramatic Reduction in Primary HIV Infection and in Recent HIV Infections in a Large French Nationwide HIV Cohort. Clinical Infectious Diseases, pii: ciz800. https://doi.org/10.1093/cid/ciz800

[43] Raifman, J., Dean, L.T., Montgomery, M.C., Almonte, A., Arrington-Sanders, R., Stein, M.D., Nunn, A.S., Sosnowy, C.D. and Chan, P.A. (2019) Racial and Ethnic Disparities in HIV Pre-Exposure Prophylaxis Awareness among Men Who Have Sex with Men. AIDS and Behavior, 23, 2706-2709. https://doi.org/10.1007/s10461-019-02462-3

[44] Amon, J.J., Eba, P., Sprague, L., Edwards, O. and Beyrer, C. (2018) Defining Rights-Based Indicators for HIV Epidemic Transition. PLOS Medicine, 15, e1002720. https://doi.org/10.1371/journal.pmed.1002720

[45] Ostrow, D.E., Fox, K.J., Chmiel, J.S., Silvestre, A., Visscher, B.R., Vanable, P.A., Jacobson, L.P. and Strathdee, S.A. (2002) Attitudes towards Highly Active Antiretroviral Therapy Are Associated with Sexual Risk Taking among HIV-Infected and Uninfected Homosexual Men. AIDS, 16, 775-780.

https://doi.org/10.1097/00002030-200203290-00013

[46] Laporte, A. (2002) A New Decline in Preventive Behaviours among Homosexual Men: The Role of Highly Active Antiretroviral Therapy? Surveillance, 7, 349. https://doi.org/10.2807/esm.07.02.00349-en

[47] Holt, M., Lea, T., Mao, L., et al. (2018) Community-Level Changes in Condom Use and Uptake of HIV Pre-Exposure Prophylaxis by Gay and Bisexual Men in Melbourne and Sydney, Australia: Results of Repeated Behavioural Surveillance in 2013-17. The Lancet HIV, 5, e448-e456. https://doi.org/10.1016/S2352-3018(18)30072-9

[48] Heuker, J., Sonder, G.J., Stolte, I., Geskus, R. and van den Hoek, A. (2012) High 
HIV Incidence among MSM Prescribed Postexposure Prophylaxis, 2000-2009: Indications for Ongoing Sexual Risk Behaviour. AIDS, 26, 505-512. https://doi.org/10.1097/QAD.0b013e32834f32d8

[49] Bezemer, D., de Wolf, F., Boerlijst, M.C., van Sighem, A., Hollingsworth, T.D., Prins, M., Geskus, R.B., Gras, L., Coutinho, R.A. and Fraser, C. (2008) A Resurgent HIV-1 Epidemic among Men Who Have Sex with Men in the Era of Potent Antiretroviral Therapy. AIDS, 22, 1071-1077. https://doi.org/10.1097/QAD.0b013e3282fd167c

[50] Stolte, I.G., Dukers, N.H., Geskus, R.B., Coutinho, R.A. and de Wit, J.B. (2004) Homosexual Men Change to Risky Sex When Perceiving Less Threat of HIV/AIDS since Availability of Highly Active Antiretroviral Therapy: A Longitudinal Review. AIDS, 18, 303-309. https://doi.org/10.1097/00002030-200401230-00021

[51] Jaffe, H.W., Valdiserri, R.O. and De Cock, K.M. (2007) The Reemerging HIV/AIDS Epidemic in Men Who Have Sex with Men. JAMA, 298, 2412-2414.

https://doi.org/10.1001/jama.298.20.2412

[52] European Centre for Disease Prevention and Control (2013) STI and HIV Prevention in Men Who Have Sex with Men in Europe. ECDC, Stockholm.

[53] Traeger, M., Cornelisse, V., Asselin, J., et al. (2019) Association of HIV Preexposure Prophylaxis with Incidence of Sexually Transmitted Infections among Individuals at High Risk of HIV Infection. JAMA, 321, 1380-1390. https://doi.org/10.1001/jama.2019.2947

[54] Desai, M., Field, N., Grant, R. and McCormack, S. (2017) State of the Art Review: Recent Advances in PrEP for HIV. BMJ, 359, j5011. https://doi.org/10.1136/bmj.j5011

[55] Kramer, S.C., Schmidt, A.J., Berg, R.C., Furegato, M., Hospers, H., Folch, C., Marcus, U. and EMIS Network (2016) Factors Associated with Unprotected Anal Sex with Multiple Non-Steady Partners in the Past 12 Months: Results from the European Men-Who-Have-Sex-With-Men Internet Survey (EMIS 2010). BMC Public Health, 16, Article No. 47. https://doi.org/10.1186/s12889-016-2691-Z

[56] Nicoll, A. and Hamers, F.F. (2002) Are Trends in HIV, Gonorrhoea, and Syphilis Worsening in Western Europe? BMJ, 324, 1324-1327. https://doi.org/10.1136/bmj.324.7349.1324

[57] European Centre for Disease Prevention and Control (2019) Syphilis and Congenital Syphilis in Europe: A Review of Epidemiological Trends (2007-2018) and Options for Response. ECDC, Stockholm.

[58] European Centre for Disease Prevention and Control (2018) Syphilis. ECDC. Annual Epidemiological Report for 2016. ECDC, Stockholm.

[59] Robert-Koch-Institute (2015) HIV, Hepatitis B und C bei infizierenden Drogengebrauchenden in Deutschland-Ergebnisse der DRUCK-Studie des RKI. Epidemiologisches Bulletin, 22, 191-197. (In German)

[60] Centers for Disease Control and Prevention (CDC) (2011) Sexual Transmission of Hepatitis C Virus among HIV-Infected Men Who Have Sex with Men-New York City, 2005-2010. Morbidity and Mortality Weekly Report, 60, 945-950.

[61] CDC 24/7 (2017) Syphilis. Sexually Transmitted Disease Surveillance 2017. https://www.cdc.gov/std/stats17/syphilis.htm

[62] Robert-Koch-Institute (RKI) (2018) Syphilis in Deutschland im Jahr 2017; Anstieg von Syphilis-Infektionen bei Männern, die Sex mit Männern haben, setzt sich weiter fort. Epidemiologisches Bulletin, 46, 493-504. (In German) 
[63] Urbanus, A.T., van Houdt, R., van de Laar, T.J. and Coutinho, R.A. (2009) Viral Hepatitis among Men Who Have Sex with Men, Epidemiology and Public Health Consequences. Surveillance, 14, 19421. https://doi.org/10.2807/ese.14.47.19421-en

[64] Popper, K. (2003) Open Society and Their Enemies. 8. Auflage J.C.B. Mohr Paul Siebeck, Tübingen, ISB 3-16-148069-4. (In German)

[65] Frieden, T.R., Das-Douglas, M., Kellerman, S.E. and Henning, K.J. (2005) Applying Public Health Principles to the HIV Epidemic. The New England Journal of Medicine, 353, 2397-2402. https://doi.org/10.1056/NEJMsb053133

[66] Bracchi, M., Stuart, D., Castles, R., Khoo, S., Back, D. and Boffito, M. (2015) Increasing Use of "Party Drugs" in People Living with HIV on Antiretrovirals: A Concern for Patient Safety. AIDS, 29, 1585-1592. https://doi.org/10.1097/QAD.0000000000000786

[67] Giorgetti, R., Tagliabracci, A., Schifano, F., Zaami, S., Marinelli, E. and Busardò, F.P. (2017) When “Chems” Meet Sex: A Rising Phenomenon Called "ChemSex". Current Neuropharmacology, 15, 762-770. https://doi.org/10.2174/1570159X15666161117151148

[68] Schwetz, T.A., Calder, T., Rosenthal, E., Kattakuzhy, S. and Fauci, A.S. (2019) Opioids and Infectious Diseases: A Converging Public Health Crisis. The Journal of Infectious Diseases, 220, 346-349. https://doi.org/10.1093/infdis/jiz133

[69] Pakianathan, M., Whittaker, W., Lee, M.J., Avery, J., Green, S., Nathan, B. and Hegazit, A. (2018) Chemsex and New HIV Diagnosis in Gay, Bisexual and Other Men Who Have Sex with Men Attending Sexual Health Clinics. HIV Medicine. https://doi.org/10.1111/hiv.12629

[70] Pufall, E.L., Kall, M., Shahmanesh, M., Nardone, A., Gilson, R., Delpech, V. and Ward, H. (2018) Sexualized Drug Use ("Chemsex") and High-Risk Sexual Behaviours in HIV-Positive Men Who Have Sex with Men. HIV Medicine, 19, 261-270. https://doi.org/10.1111/hiv.12574

[71] González-Baeza, A., Dolengevich-Segal, H., Pérez-Valero, I., et al. (2018) Sexualized Drug Use (Chemsex) Is Associated with High-Risk Sexual Behaviors and Sexually Transmitted Infections in HIV-Positive Men Who Have Sex with Men: Data from the U-SEX GESIDA 9416 Study. AIDS Patient Care STDS, 32, 112-118. https://doi.org/10.1089/apc.2017.0263

[72] Bouvin-Pley, M., Beretta, M., Moreau, A., et al. (2019) Evolution of the Envelope Glycoprotein of HIV-1 Clade B toward Higher Infectious Properties over the Course of the Epidemic. Journal of Virology, 93, pii: e01171-18. https://doi.org/10.1128/JVI.01171-18

[73] Wirden, M., De Oliveira, F., Bouvier-Alias, M., et al. (2019) New HIV-1 Circulating Recombinant form 94: From Phylogenetic Detection of a Large Transmission Cluster to Prevention in the Age of Geosocial-Networking Apps in France, 2013 to 2017. Surveillance, 24, 1800658. https://doi.org/10.2807/1560-7917.ES.2019.24.39.1800658

[74] Delgado, E., Benito, S., Montero, V., et al. (2019) Diverse Large HIV-1 Non-Subtype B Clusters Are Spreading among Men Who Have Sex with Men in Spain. Frontiers in Microbiology, 10, 655. https://doi.org/10.3389/fmicb.2019.00655

[75] Patiño-Galindo, J.Á., Domínguez, F., Cuevas, M.T., et al. (2018) Genome-Scale Analysis of Evolutionary Rate and Selection in a Fast-Expanding Spanish Cluster of HIV-1 Subtype F1. Infection, Genetics and Evolution, 66, 43-47. https://doi.org/10.1016/j.meegid.2018.09.008

[76] Kusejko, N., Bachmann, N., Chaudron, S.E., et al. (2019) A Systematic Phylogenetic Approach to Study the Interaction of HIV-1 with Coinfections, Non-Communicable 
and Opportunistic Diseases. The Journal of Infectious Diseases, 220, 244-253. https://doi.org/10.1093/infdis/jiz093

[77] Stevens, O., Moncrieff, M. and Gafos, M. (2019) Chemsex-Related Drug Use and Its Association with Health Outcomes in Men Who Have Sex with Men: A Cross-Sectional Analysis of Antidote Clinic Service Data. Sexually Transmitted Infections, pii: sextrans-2019-054040. https://doi.org/10.1136/sextrans-2019-054040

[78] Beck U. Risk Society (1992) Towards a New Modernity. SAGE Publications Ltd., London.

[79] UNAIDS Reference Group on HIV and Human Rights (2009) Recommendations Brief to Michel Sidibe, UNAIDS Executive Director.

http://data.unaids.org/pub/basedocument/2009/20090302_hrrefgroupsidibebriefeng _en.pdf

[80] Long, E.F., Brandeau, M.L. and Owens, D.K. (2010) The Cost-Effectiveness and Population Outcomes of Expanded HIV Screening and Antiretroviral Treatment in the United States. Annals of Internal Medicine, 153, 778-789.

https://doi.org/10.7326/0003-4819-153-12-201012210-00004

[81] De Francesco, D., Verboeket, S.O., Underwood, J., et al. (2018) Patterns of Co-Occurring Comorbidities in People Living with HIV. Open Forum Infectious Diseases, 5, ofy272. https://doi.org/10.1093/ofid/ofy272

[82] Glass, R.I. (2014) HIV/AIDS and Noncommunicable Disease Comorbidities: Emerging Research Priorities. JAIDS Journal of Acquired Immune Deficiency Syndromes, 67, S1. https://doi.org/10.1097/QAI.0000000000000266

[83] Jin, F., Vajdic, C.M., Law, M., Amin, J., van Leeuwen, M., McGregor, S., Poynten, I.M., Templeton, D.J. and Grulich, A.E. (2019) Incidence and Time Trends of Anal Cancer among People Living with HIV in Australia. AIDS, 33, 1361-1368.

https://doi.org/10.1097/QAD.0000000000002218

[84] Bosh, K.A., Crepaz, N., Dong, X., Lyss, S., Mendoza, M. and Mitsch, A.J. (2019) Opioid Overdose Deaths among Persons with HIV Infection, United States, 2011-2015. Conference on Retroviruses and Opportunistic Infections, 4-7 March 2019, Seattle, Abstract Number: 147.

http://www.croiconference.org/sessions/opioid-overdose-deaths-among-persons-hi v-infection-united-states-2011-2015

[85] HIV.gov (2019) Other Health Issues of Special Concern for People Living with HIV. https://www.hiv.gov/hiv-basics/staying-in-hiv-care/other-related-health-issues/othe r-health-issues-of-special-concern-for-people-living-with-hiv

[86] Thakur, K.T., Boubour, A., Saylor, D., Das, M., Bearden, D. and Birbeck, G.L. (2019) Global HIV Neurology: A Comprehensive Review. AIDS, 33, 163-184. https://doi.org/10.1097/QAD.0000000000001796

[87] Rosenthal, J. and Tyor, W.R. (2019) Aging, Comorbidities, and the Importance of Finding Biomarkers for HIV-Associated Neurocognitive Disorders. Journal of NeuroVirology, 25, 673-685. https://doi.org/10.1007/s13365-019-00735-0

[88] Azoulay, É., de Castro, N. and Barbier, F. (2019) Critically Ill Patients with HIV: 40 Years Later. Chest, pii: S0012-3692(19)31453-9. https://doi.org/10.1016/j.chest.2019.08.002

[89] Petruzziello, A., Loquercio, G., Sabatino, R., et al. (2019) Prevalence of Hepatitis C Virus Genotypes in Nine Selected European Countries: A Systematic Review. Journal of Clinical Laboratory Analysis, 33, e22876. https://doi.org/10.1002/jcla.22876

[90] Ramière, C., Charre, C., Miailhes, P., et al. (2019) Patterns of HCV Transmission in 
HIV-Infected and HIV-Negative Men Having Sex with Men. Clinical Infectious Diseases, 69, 2127-2135. https://doi.org/10.1093/cid/ciz160

[91] Charre, C., Cotte, L., Kramer, R., Miailhes, P., Godinot, M., Koffi, J., Scholtès, C. and Ramière, C. (2018) Hepatitis C Virus Spread from HIV-Positive to HIV-Negative Men Who Have Sex with Men. PLoS ONE, 13, e0190340. https://doi.org/10.1371/journal.pone.0190340

[92] Lerner, A.M., Eisinger, R.W. and Fauci, A.S. (2020) Comorbidities in Persons with HIV: The Lingering Challenge. JAMA, 323, 19-20. https://doi.org/10.1001/jama.2019.19775

[93] Schroeder, S.E., Higgs, P., Winter, R., Brown, G., Pedrana, A., Hellard, M., Doyle, J. and Stoové, M. (2019) Hepatitis C Risk Perceptions and Attitudes towards Reinfection among HIV-Diagnosed Gay and Bisexual Men in Melbourne, Australia. Journal of the International AIDS Society, 22, e25288. https://doi.org/10.1002/jia2.25288

[94] van de Laar, T.J., Matthews, G.V., Prins, M. and Danta, M. (2010) Acute Hepatitis C in HIV-Infected Men Who Have Sex with Men: An Emerging Sexually Transmitted Infection. AIDS, 24, 1799-1812. https://doi.org/10.1097/QAD.0b013e32833c11a5

[95] AASLD, IDSA, (2020) HCV Guidance: Recommendations for Testing, Managing, and Treating Hepatitis C. Last Updated: November 6, 2019.

https://www.hcvguidelines.org/sites/default/files/full-guidance-pdf/200206_HCVGu idance_November_06_2019_a.pdf

[96] Conference Reports of NATAP (2016) Hepatitis C Virus Reinfection Incidence and Outcomes among HIV-Positive MSM in Western Europe. The International Liver Congress $^{\text {TM }}$ EASL European Association for the Study of the Liver, Barcelona, 13-17 April 2016. http://www.natap.org/2016/EASL/EASL_12.htm

[97] Lacombe, K. (2019) Lessons from France on Implementing HCV Treatment as Prevention: Whom Should We Treat and How?

https://www.clinicaloptions.com/hepatitis/programs/hcv-treatment-as-prevention/c linicalthought

[98] Popping, S., Cento, V., García, F., Ceccherini-Silberstein, F., Seguin-Devaux, C., van de AMC Vijver, D. and Boucher Ch, A. (2018) The Need for a European Hepatitis C Programme Monitoring Resistance to Direct-Acting Antiviral Agents in Real Life to Eliminate Hepatitis C. Journal of Virus Eradication, 4, 179-181.

[99] Sweeney, S., Ward, Z., Platt, L., et al. (2019) Evaluating the Cost-Effectiveness of Existing Needle and Syringe Programmes in Preventing Hepatitis C Transmission in People Who Inject Drugs. Addiction, 114, 560-570. https://doi.org/10.1111/add.14519

[100] Pericàs, J.M., Bromberg, D.J., Ocampo, D., Schatz, E., Wawer, I., Wysocki, P., Safreed-Harmon, K. and Lazarus, J.V. (2019) Hepatitis C Services at Harm Reduction Centres in the European Union: A 28-Country Survey. Harm Reduction Journal, 16, 20. https://doi.org/10.1186/s12954-019-0290-X

[101] Trickey, A., Fraser, H., Lim, A.G., et al. (2019) The Contribution of Injection Drug Use to Hepatitis C Virus Transmission Globally, Regionally, and at Country Level: A Modelling Study. The Lancet Gastroenterology and Hepatology, 4, 435-444. https://doi.org/10.1016/S2468-1253(19)30085-8

[102] Li, J., Gilmour, S., Zhang, H., Koyanagi, A. and Shibuya, K. (2012) The Epidemiological Impact and Cost Effectiveness of HIV Testing, Antiretroviral Treatment and Harm Reduction Programs. AIDS, 26, 2069-2078. https://doi.org/10.1097/QAD.0b013e3283574e54

[103] Eaton, E.F., Tamhane, A., Saag, M., Mugavero, M.J. and Kilgore, M.L. (2016) Cost 
Consideration in the Current Antiretroviral Era. AIDS, 30, 2115-2119. https://doi.org/10.1097/QAD.0000000000001120

[104] Linderhill, K. (2012) Paying for Prevention: Challenges to Health Insurance Coverage for Medical HIV Prevention in the United States. The American Journal of Law \& Medicine, 38, 607-666. https://doi.org/10.1177/009885881203800402

[105] Krebs, E., Zang, X., Enns, B., et al. (2019) The Impact of Localized Implementation: Determining the Cost-Effectiveness of HIV Prevention and Care Interventions across Six United States Cities. AIDS, 34, 447-458. https://doi.org/10.1097/QAD.0000000000002455

[106] Centers for Disease Control and Prevention (2011) Sexual Transmission of Hepatitis C Virus among HIV-Infected Men Who Have Sex with Men-New York City, 2005-2010. $M M W R, 60,945-950$.

[107] Pradat, P., Huleux, T., Raffi, F., et al. (2018) Incidence of New Hepatitis C Virus Infection Is Still Increasing in French MSM Living with HIV. AIDS, 32, 1077-1082. https://doi.org/10.1097/QAD.0000000000001789

[108] Martin, T.C., Martin, N.K., Hickman, M., Vickerman, P., Page, E.E., Everett, R., Gazzard, B.G. and Nelson, M. (2013) Hepatitis C Virus Reinfection Incidence and Treatment Outcome among HIV-Positive MSM. AIDS, 27, 2551-2557. https://doi.org/10.1097/QAD.0b013e32836381cc

[109] Berenguer, J., Gil-Martin, Á., Jarrin, I., et al. (2019) Reinfection by Hepatitis C Virus Following Effective All-Oral Direct-Acting Antiviral Drug Therapy in HIV/Hepatitis C Virus Coinfected Individuals. AIDS, 33, 685-689. https://doi.org/10.1097/QAD.0000000000002103

[110] Hajarizadeh, B., Cunningham, E.B., Valerio, H., et al. (2019) Hepatitis C Reinfection after Successful Antiviral Treatment among People Who Inject Drugs: A Meta-Analysis. Journal of Hepatology. https://doi.org/10.1016/j.jhep.2019.11.012

[111] AVERT (2019) HIV Prevention Programmes Overview. https://www.avert.org/professionals/hiv-programming/prevention

[112] Bhatia, T., Enoch, J., Khan, M., Mathewson, S., Heymann, D., Hayes, R. and Dar, O. (2019) Setting Targets for HIV/AIDS-What Lessons Can Be Learned from Other Disease Control Programmes? PLOS Medicine, 16, e1002735. https://doi.org/10.1371/journal.pmed.1002735

[113] Fauci, A.S., Redfield, R.R., Sigounas, G., Weahkee, M.D. and Giroir, B.P. (2019) Ending the HIV Epidemic: A Plan for the United States. JAMA, 321, 844-845. https://doi.org/10.1001/jama.2019.1343

[114] Brown, T. and Peerapatanapokin, W. (2019) Evolving HIV Epidemics: The Urgent Need to Refocus on Populations with Risk. Current Opinion in HIV and AIDS, 14, 337-353. https://doi.org/10.1097/COH.0000000000000571

[115] Mayer, K.H. and Allan-Blitz, L.-T. (2019) Similar, But Different: Drivers of the Disproportionate HIV and Sexually Transmitted Infection Burden of Key Populations. Journal of the International AIDS Society, 22, e25344. https://doi.org/10.1002/jia2.25344

[116] Verhofstede, C., Mortier, V., Dauwe, K., et al. (2019) Exploring HIV-1 Transmission Dynamics by Combining Phylogenetic Analysis and Infection Timing. Viruses, 11, pii: E 1096. https://doi.org/10.3390/v11121096

[117] HIV.gov. (2019) National HIV Testing Day. Results of Partnership Work at National HIV Testing Day 2019 Show That Local Engagement in HIV Testing Matters. https://www.hiv.gov/topics/hivtestingday 
https://www.hiv.gov/blog/recapping-national-hiv-testing-day-2019

[118] Ghimire, S., Hallett, J., Gray, C., Lobo, R. and Crawford, G. (2019) What Works? Prevention and Control of Sexually Transmitted Infections and Blood-Borne Viruses in Migrants from Sub-Saharan Africa, Northeast Asia and Southeast Asia Living in High-Income Countries: A Systematic Review. International Journal of Environmental Research and Public Health, 16, E1287. https://doi.org/10.3390/ijerph16071287

[119] Hachfeld, A., Darling, K., Calmy, A., et al. (2019) Why Do Sub-Saharan Africans Present Late for HIV Care in Switzerland? HIV Medicine, 20, 418-423. https://doi.org/10.1111/hiv.12727

[120] Zhu, W., Bazzi, S.A. and Bazzi, A.R. (2019) Behavioral Changes Following HIV Seroconversion during the Historical Expansion of HIV Treatment in the United States. AIDS, 33, 113-121. https://doi.org/10.1097/QAD.0000000000002048

[121] Wu, Z., Tang, Z., Mao, Y., et al. (2017) Testing and Linkage to HIV Care in China: A Cluster-Randomised Trial. The Lancet HIV, 4, e555-e565. https://doi.org/10.1016/S2352-3018(17)30131-5

[122] National Institute of Allergy and Infectious Diseases (NIAID, USA) (2019) Connection to HIV Care Helps Hardly Reached US Populations Suppress the Virus. NIH-Funded Study Evaluated Strategies to Identify and Support Men Who Have Sex with Men and Transgender Women with Unsuppressed HIV.

https://www.niaid.nih.gov/news-events/connection-hiv-care-helps-hardly-reachedus-populations-suppress-virus

[123] Zang, X., Krebs, E., Min, J.E., et al. (2020) Development and Calibration of a Dynamic HIV Transmission Model for 6 US Cities. Medical Decision Making, 40, 3-16. https://doi.org/10.1177/0272989X19889356

[124] Lockard, A., Rosenberg, E.S., Sullivan, P.S., Kelley, C.F., Serota, D.P., Rolle, C.M., Luisi, N., Pingel, E. and Siegler, A.J. (2019) Contrasting Self-Perceived Need and Guideline-Based Indication for HIV Pre-Exposure Prophylaxis among Young, Black Men Who Have Sex with Men Offered Pre-Exposure Prophylaxis in Atlanta, Georgia. AIDS Patient Care and STDs, 33, 112-119. https://doi.org/10.1089/apc.2018.0135

[125] Ong, J.J., Baggaley, R.C., Wi, T.E., et al. (2019) Global Epidemiologic Characteristics of Sexually Transmitted Infections among Individuals Using Preexposure Prophylaxis for the Prevention of HIV Infection a Systematic Review and Meta-Analysis. JAMA Network Open, 2, e1917134.

https://doi.org/10.1001/jamanetworkopen.2019.17134

[126] Medina-Perucha, L., Family, H., Scott, J., et al. (2019). Factors Associated with Sexual Risks and Risk of STIs, HIV and Other Blood-Borne Viruses among Women Using Heroin and Other Drugs: A Systematic Literature Review. AIDS and Behavior, 23, 222-251. https://doi.org/10.1007/s10461-018-2238-7

[127] HIV.gov. (2019) What Is "Ending the HIV Epidemic: A Plan for America"? https://www.hiv.gov/federal-response/ending-the-hiv-epidemic/overview 